\title{
Photovoltaic charging multi-station with modular architecture for Light Electric Vehicles
}

\author{
Guillén-Arenas, Francisco Jesús ${ }^{1}$, Fernández-Ramos, José ${ }^{1}$ and Gago-Calderón, Alfonso ${ }^{2}$ \\ ${ }^{1}$ Departmento de Electrónica \\ Escuela de Ingenierías Industriales, Universidad de Málaga \\ Complejo Tecnológico de Teatinos 2.2.41, 29071 Málaga (Spain) \\ Phone number:+0034 952 131441, e-mail: josefer@ctima.uma.es, \\ ${ }^{2}$ Departmento de Expresión Gráfica, Diseño y Proyectos \\ Escuela de Ingenierías Industriales, Universidad de Málaga \\ Calle Doctor Ortiz Ramos s/n, 29071 Málaga (Spain) \\ Phone number:+0034 951 952274, e-mail: agago@uma.es,
}

\begin{abstract}
.
This paper deals with a modular architecture for recharging the batteries of light electric vehicles (LEVs) using a photovoltaic (PV) generator.

The architecture is organized into two hierarchical levels. At the top level (master), a microcontroller tracks the maximum power point of the PV generator. This microcontroller executes a proportional-integral-derivative (PID) control algorithm whose output is the setpoint of the microcontrollers of the lower level. At the lower level (slaves), there is a microcontroller for each vehicle charging station. Each microcontroller controls the recharge current of the vehicle battery connected to the station by executing another PID control algorithm. Modular architecture allows the number of charging stations to be extended up to 112 . Other characteristics of the system are the automatic detection of the nominal voltage of the battery (it allows to recharge batteries of $24 \mathrm{~V}, 36 \mathrm{~V}$ or $48 \mathrm{~V}$ ) and the inclusion of protection functions as battery overload or detection of not allowed batteries.
\end{abstract}

\section{Key words}

Light Electric vehicle, Photovoltaic Energy, EV charging system, Solar parking lots, Sustainable mobility

\section{Introduction}

Nowdays, sustainable mobility is one of the great challenges of modern densely populated cities. In this framework, the electric vehicle (EV) is presented as the best solution to this problem [1]. However, the introduction of EVs as the main means of transport in cities also presents serious problems. One of the most important problems is the impact on the distribution grid of electric power [2-4]. A significant increase in the number of urban EVs can cause overloads in the grid, voltage and / or efficiency drops and, in the worst case, their collapse.

One of the many solutions provided to this problem is the use of PV generators as charging stations [5]. PV recharge stations located in parkings [6-7] and in the workplaces [8] are proposed as an extent to minimize the impact on the grid of the EVs charging stations.

However, the high capacity of modern EVs batteries prevents them from being recharged using only a PV generator. According to this, the proposals of PV recharge stations present a hybrid solution between the PV generator and the grid [9-10].

In this context, Light Electric Vehicles (LEVs) [11] are presented as an efficient alternative to the use of heavier EVs in urban mobility. There is a wide variety of LEVs (bicycles, mopeds, motorcycles, tricycles and fourwheeled), but all have in common a low weight (E.g. 75 $\mathrm{kg}$ for one passenger vehicles and $150 \mathrm{~kg}$ for two passenger vehicles), low power consumption (normally less than $100 \mathrm{Wh}$ per kilometer) and a low voltage battery $(24 \mathrm{~V}, 36 \mathrm{~V}$ or $48 \mathrm{~V}$ as nominal voltages).

The reduced consumption of the LEVs make them ideal to be recharged in stations that use only PV energy, without the need to be connected to the grid, so the impact on it is null.

This paper presents a PV charging multi-station for LEVs whose main characteristics are:

- Modular design. The architecture supports a variable number of charging stations between 1 and 112 .

- It allows simultaneous recharging of batteries of different nominal voltages: $24 \mathrm{~V}, 36 \mathrm{~V}$ and $48 \mathrm{~V}$

- It ensures that the PV generator operates at the maximum power point.

- It incorporates protections against battery overcharging and detection of not allowed batteries

\section{Work Methodology}

\section{A. Theory fundamentals}

The principle of operation of the system is that the current provided by the PV generator is distributed equally among all connected batteries. To do this, a double PID cascaded control has been designed. 
The first PID control is executed by the master controller to keep the PV generator at the voltage of the maximum power point. Its parameters are:

- Setpoint: Voltage of the maximum power point.

- Feedback: Actual voltage measured at the terminals of the PV system.

- PID output: Current value (setpoint) for the slave PID.

The second PID control (slave) is performed by each charging station and ensures that the current supplied to the LEV battery is equal to the setpoint provided by the master controller. Its parameters are:

- Setpoint: Current value from the master.

- Feedback: Real current value measured through a current sensor.

- PID output: Duty cycle of the signal control of the charger.

Figure 1 shows a functional diagram of the system.

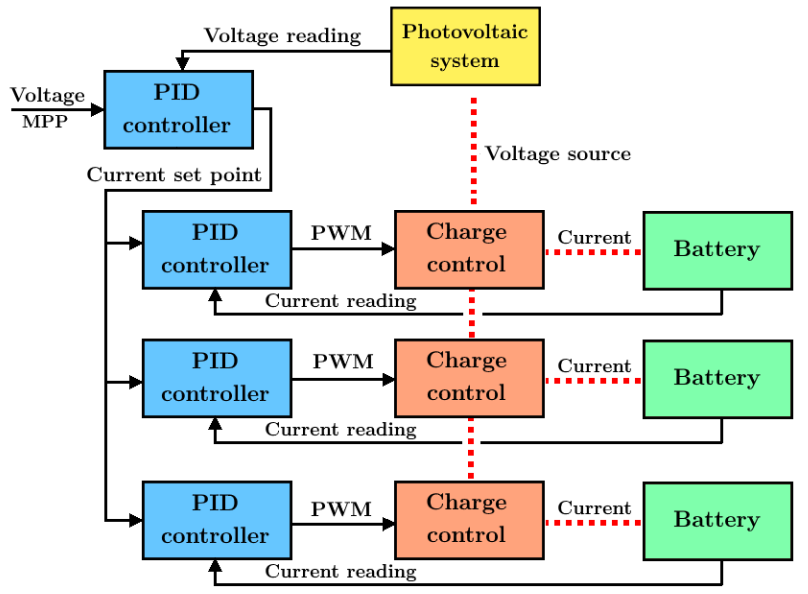

Figure 1. Functional diagram of the system.

\section{B. Hardware}

Figure 2 shows the hardware architecture of the system. The master controller measures the voltage of the generator and sends the slaves the current setpoint through the $\mathrm{I} 2 \mathrm{C}$ bus.

Each slave controller has a sensor to measure the charge current of its battery and adjust it to the setpoint value by the PID control algorithm. The regulation of the charging current is carried out by means of a PWM signal applied to the power stage. It also has a voltage sensor that is used to detect when a battery is connected and what is the value of its nominal voltage.

All controllers have been implemented using the Arduino platform. The current and the power stage have been custom designed for this project.

The communications between the controllers have been carry out using the standard $\mathrm{I} 2 \mathrm{C}$ bus integrated in Arduino, which limits the maximum number of recharging stations to 112 , more than enough for this application. If a greater robustness in the communications is required, the CAN bus or another industrial standard bus could be used.

Figure 3 shows a photo of the system formed by two charging stations that has been used to perform the operation tests.

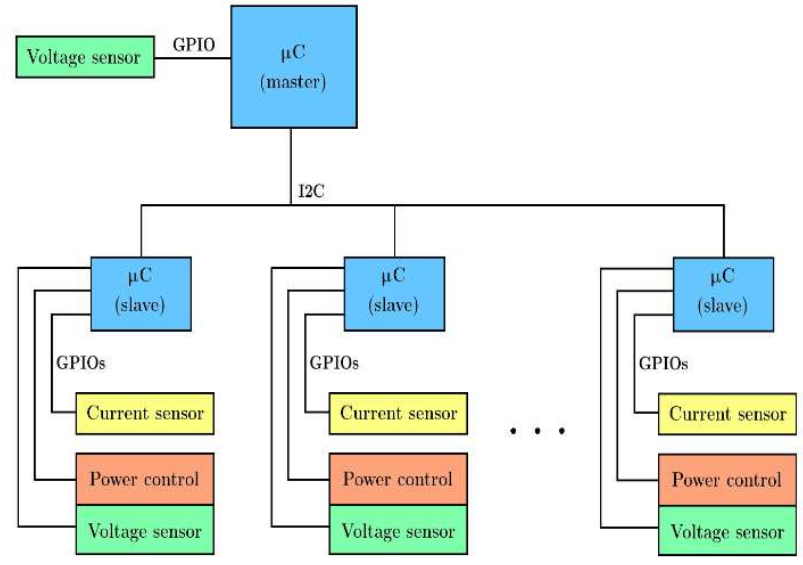

Figure 2. Hardware architecture

\section{Software}

Two control algorithms have been developed, one for the master controller and one for the slave controllers.

The master controller algorithm tracks the maximum power point of the PV generator to ensure that all available energy is used at all times. It is based on a PID control algorithm whose setpoint value is the voltage of the maximum power point of the PV generator and whose output is the charge current setpoint value of each of the batteries connected to the system. This value depends on the number of batteries that are being recharged at a given time, so that it decreases as the number of batteries increases.

To increase the stability of the system, the tuning of the parameters of the PID control has been carried out in such a way that its output (the current setpoint for the slave controllers) varies slowly, without suffering sudden changes. A consequence of this is that the voltage of the generator takes more time to reach the value of the setpoint voltage of the maximum power point.

The algorithm of the slaves is more complex, since it performs the following functions:

- Detection of whether a battery is connected and, if so, the identification of its nominal voltage to check that it corresponds to one of the three permitted types, $24 \mathrm{~V}, 36 \mathrm{~V}$ or $48 \mathrm{~V}$. In the event that the connected battery does not correspond to any of these three types, recharging will not be allowed.

- Execution of a PID control algorithm that adjusts the value of the recharge current of the battery to the setpoint value received from the master controller. A more "aggressive" tuning of the control parameters of this algorithm has been made, to ensure that the recharge current is adjusted very quickly to the setpoint, thus avoiding that "peaks" of current can occur in an excessive time interval.

- Detection of the full charge of the battery, to cut off the charge current and thus avoid its overload. 


\section{System testing and results}

To evaluate the performance of the system, a prototype consisting of a master controller and two slave controllers has been developed. Figure 3 shows a photo of this prototype.

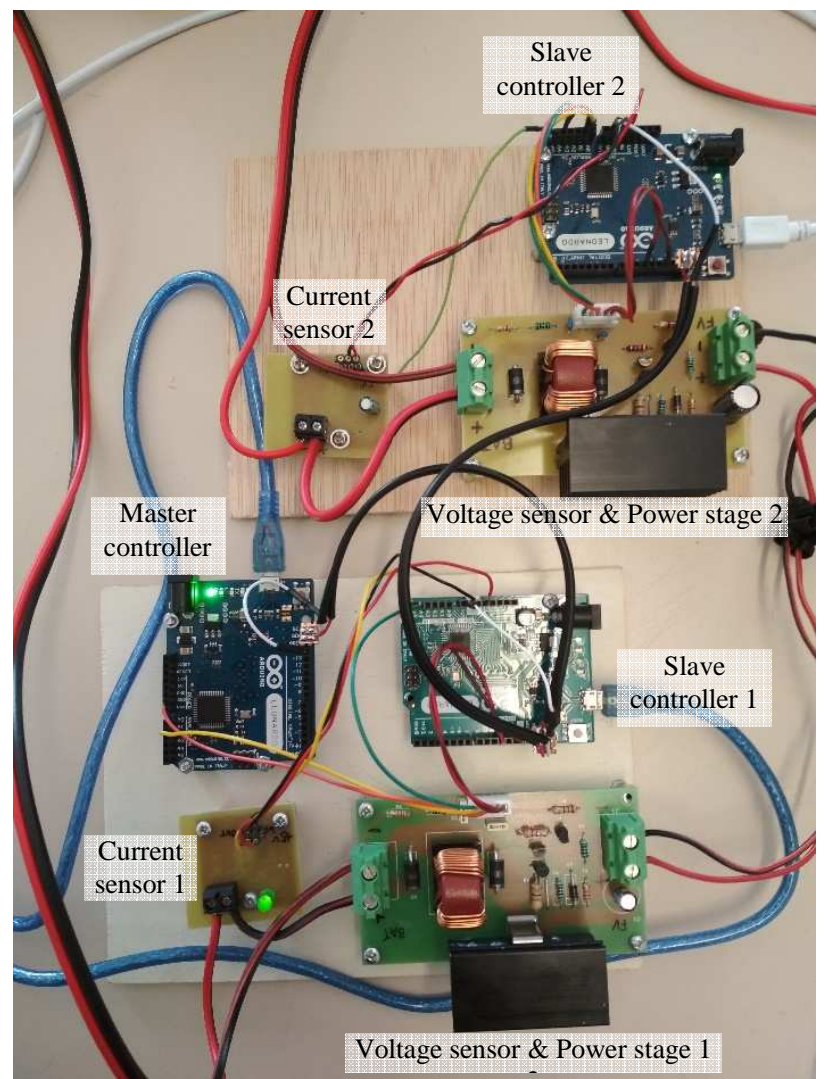

Figure 3. Prototype used for testing

A small PV generator has been used as power source of the system. Its main characteristics are $72 \mathrm{Wp}$ of power and $65 \mathrm{~V}$ of open circuit voltage (under standard conditions of $25^{\circ} \mathrm{C}$ and $1000 \mathrm{~W} / \mathrm{m}^{2}$ ). Figure 4 shows a photo of this $\mathrm{PV}$ generator.

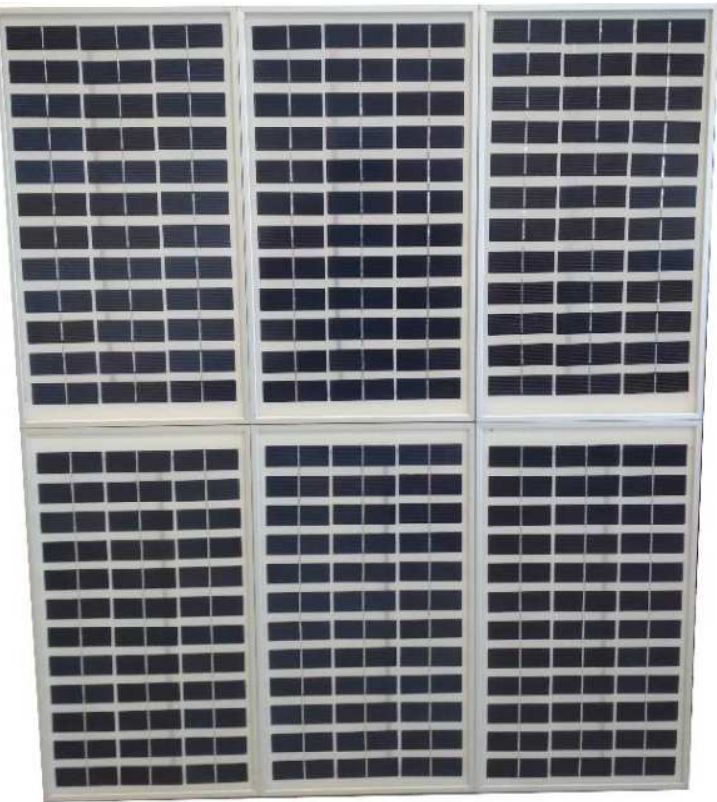

Figure 4. PV modules used for testing
A large number of tests have been carried out to set up the system.

Initially the tuning tests of the control parameters were carried out, for which $24 \mathrm{~V}, 36 \mathrm{~V}$ and $48 \mathrm{~V}$ nominal voltage batteries were used. The values obtained were the following:

Master controller: $\mathrm{Kp}=0.2 ; \mathrm{Ki}=0.03$ and $\mathrm{Kd}=0.02$

Slave controller: $\mathrm{Kp}=4 ; \mathrm{Ki}=70$ and $\mathrm{Kd}=0$

Next, performance tests were carry out in different climatic conditions and with different battery models. As an example, we have selected the test whose results are shown in Figure 5. This test was performed on a sunny day "dotted" with small clouds that caused continuous changes in the irradiance and, therefore, in the power available by the system.

The first two curves represent the voltage of the photovoltaic generator (orange) and the setpoint voltage corresponding to the maximum power point calculated by the master controller algorithm (blue).

The following two curves show the voltages at the battery charging connector 1 (blue) and the battery charging connector 2 (red).

Finally, the remaining three curves show the current setpoint generated by the master PID control algorithm (green), the charging current of battery 1 (blue) and the charging current of battery 2 (red).

\section{Discussion.}

Initially no battery was connected, so the voltage in the $\mathrm{PV}$ generator is close to $65 \mathrm{~V}$, which is the open circuit voltage. The default setpoint current under these conditions was set to $5 \mathrm{~A}$, as shown by the green curve. 15 seconds after the start, a $36 \mathrm{~V}$ battery was connected to the charger 1 , as shown by the voltage that appears in the charging connector of this charger. The charging of this battery begins immediately at the maximum duty cycle, since the difference between the current setpoint (5A) and its initial value $(0 \mathrm{~A})$ is very high. Because of this, the voltage in the PV generator suffers a sharp drop, which also causes the reduction of the current setpoint. As can be seen, the charge current of the battery 1 reaches its setpoint value much more quickly than the voltage of the photovoltaic generator, due to the way in which the tuning of both processes has been carried out.

At 62 seconds, after the voltage setpoint of the PV generator has been reached, a new $48 \mathrm{~V}$ battery has been connected to the charger 2 . In this case, the difference between the current setpoint and the charge current values on the two chargers are not so large, so the voltage drop in the photovoltaic generator is much smaller. At 123 seconds, the definitive current setpoint value is reached and the two chargers are charged with the same current. The changes that occur from that moment to 220 seconds are caused by the passage of clouds, as can be seen in the oscillations that occur in the voltage of the PV generator. It can be seen that throughout this period of time the current values in the two chargers are perfectly adjusted to the value of the setpoint, which in turn varies because of the irradiance changes. 


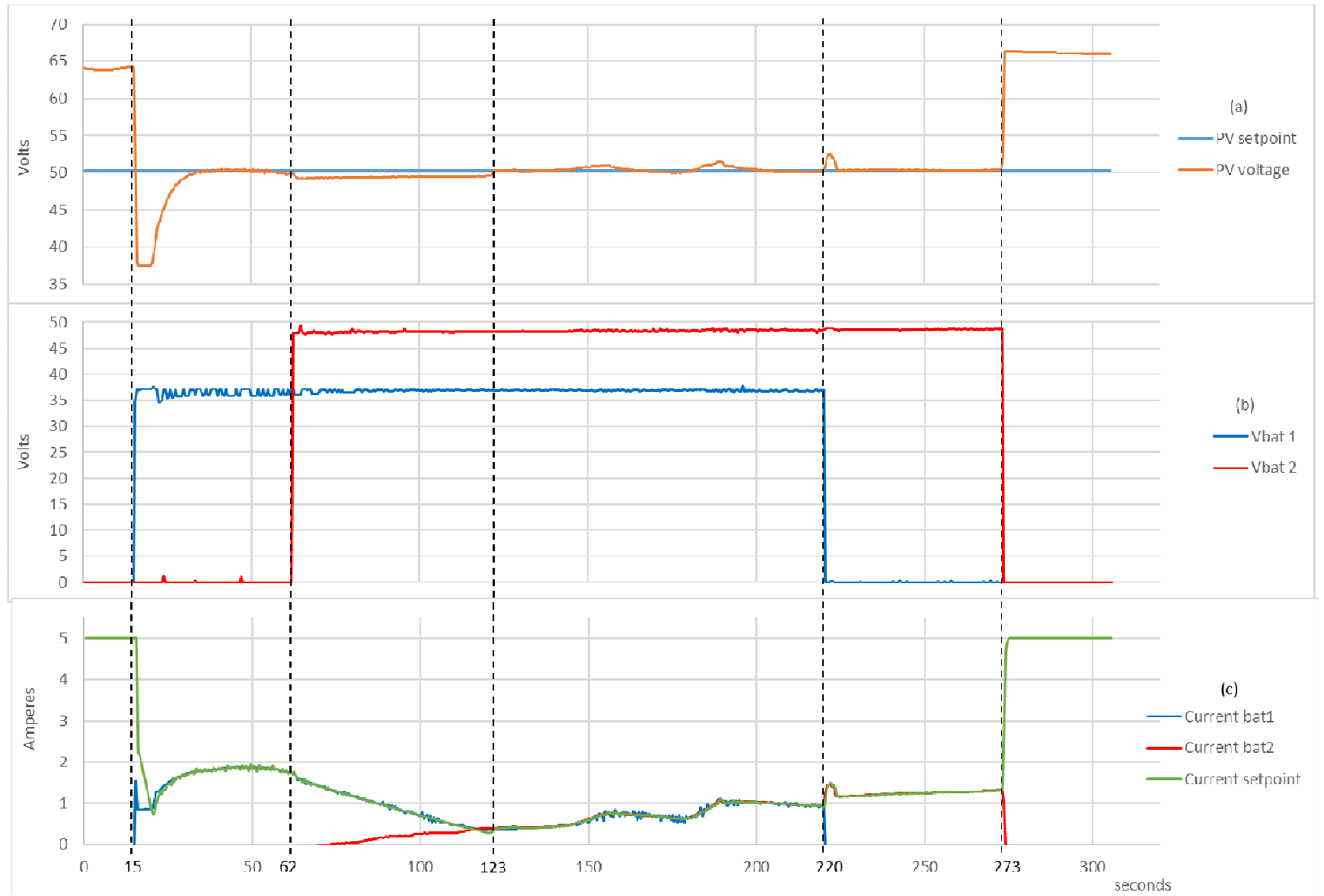

Figure 5. Example of recharging two batteries with different nominal voltage

At 220 seconds, the battery of the charger 1 has been disconnected, with the sole effect of a brief increase in the voltage at the PV generator, which returns to its setpoint again. The charging current of the battery 2 is perfectly adjusted to the setpoint throughout this time interval.

Finally, after 273 seconds, the battery of charger 2 is disconnected and the system quickly returns to its initial state.

This test proves quite clearly that the system functions correctly and meets all the specifications of the initial design.

\section{Conclusions}

It has been shown that it is possible to carry out a PV charging multi-station for batteries of LEVs based on general-purpose electronic components that optimizes the use of the available energy in the PV generator.

The design is modular, which allows adding more chargers without modifying the structure of the system.

Other characteristics of the system are the automatic detection of the nominal voltage of the battery (it allows to recharge batteries of $24 \mathrm{~V}, 36 \mathrm{~V}$ or $48 \mathrm{~V}$ ) and the inclusion of protection functions as battery overload or detection of not allowed batteries.

The tests that have been carried out have shown optimal performance in conditions of variable irradiance (passage of clouds) and when a simultaneous recharge of batteries with different nominal voltage is performed.

\section{Acknowledgement}

This work is part of an educational innovation project financed by the Universidad de Málaga within its programs 2015-2017 (PIE15-122) and 2017-2019 (PIE17-120)

\section{References}

[1] Siang Fui Tie, Chee Wei Tan, "A review of energy sources and energy management system in electric vehicles", Renewable and Sustainable Energy Reviews, 2013, Vol. 20, pp. 82-102,

[2] R. C. Green, L. Wang and M. Alam, "The impact of plug-in hybrid electric vehicles on distribution networks: a review and outlook," IEEE PES General Meeting, Providence, RI, 2010, pp. 1-8.

[3] S. Shao, M. Pipattanasomporn and S. Rahman, "Challenges of PHEV penetration to the residential distribution network," 2009 IEEE Power \& Energy Society General Meeting, Calgary, AB, 2009, pp. 1-8.

[4] K. Clement-Nyns, E. Haesen and J. Driesen, "The Impact of Charging Plug-In Hybrid Electric Vehicles on a Residential Distribution Grid," in IEEE Transactions on Power Systems, vol. 25, no. 1, pp. 371-380, Feb. 2010.

[5] Abdul Rauf Bhatti, Zainal Salam, Mohd Junaidi Bin Abdul Aziz, Kong Pui Yee, Ratil H. Ashique, "Electric vehicles charging using photovoltaic: Status and technological review", Renewable and Sustainable Energy Reviews, Vol 54, pp. 34-47 [6] Pedro Nunes, Raquel Figueiredo, Miguel C. Brito, "The use of parking lots to solar-charge electric vehicles", Renewable and Sustainable Energy Reviews, Vol 66, pp. 679-693 
[7] Raquel Figueiredo, Pedro Nunes, Miguel C. Brito, "The feasibility of solar parking lots for electric vehicles", Energy, Vol 140, Part 1, pp. 1182-1197

[8] G.R. Chandra Mouli, P. Bauer, M. Zeman, "System design for a solar powered electric vehicle charging station for workplaces", Applied Energy, Vol 168, pp. 434-443

[9] Pedro Nunes, Tiago Farias, Miguel C. Brito, "Enabling solar electricity with electric vehicles smart charging",Energy, Vol 87, pp. $10-20$

[10] Lei Shi, Haiping Xu, Dongxu Li, Zuzhi Zhang and Yuchen Han, "The photovoltaic charging station for electric vehicle to grid application in Smart Grids," 2012 IEEE 6th International Conference on Information and Automation for Sustainability, Beijing, 2012, pp. 279-284.

[11] Van den Bossche, Alex, Peter Sergeant, and Isabelle Hofman, "Towards Low Energy Mobility Using Light and Ultralight Electric Vehicles.", First International Conference On Electromechanical Engineering, Proceedings. Ed. Abderrezak Metatla. University of Skikda Algeria, 2012 